Article

\title{
Are Korean Households Willing to Pay a Premium for Induction Cooktops over Gas Stoves?
}

\author{
Hyo-Jin Kim, Seul-Ye Lim and Seung-Hoon Yoo * \\ Department of Energy Policy, Graduate School of Energy \& Environment, \\ Seoul National University of Science \& Technology, 232 Gongreung-Ro, Nowon-Gu, Seoul 01811, Korea; \\ hjinkim@seoultech.ac.kr (H.-J.K.); sylim@seoultech.ac.kr (S.-Y.L.) \\ * Correspondence: shyoo@seoultech.ac.kr; Tel.: +82-2-970-6802
}

Received: 16 July 2017; Accepted: 23 August 2017; Published: 30 August 2017

\begin{abstract}
Korean households generally prefer to use induction cooktops rather than gas stoves because of their greater convenience and safety features. This paper tries to investigate whether Korean households are willing to pay a premium for replacing their gas stoves, which are currently common in Korea, with induction cooktops, from the perspective of convenience and safety. To this end, a contingent valuation technique was applied to assess the additional willingness to pay (WTP) a premium for using an induction cooktop rather than a gas stove. A nationwide survey of 1000 households was carried out. The results indicate that the mean additional WTP for using an induction cooktop rather than a gas stove is KRW 207 (USD 0.19) per cubic meter of residential gas. This value can be interpreted as the convenience and safety benefits to the consumer of using an induction cooktop rather than a gas stove, or residential electricity rather than residential gas for cooking. It amounts to approximately $26.7 \%$ of the average 2015 price of residential gas, which was KRW 775 (USD 0.70) per cubic meter. If the gap between the price for residential electricity and the price for residential gas is less than the WTP value, households will increase their demand for residential electricity for cooking.
\end{abstract}

Keywords: induction cooktop; gas stove; convenience; safety; premium; willingness to pay

\section{Introduction}

Gas stoves, which use natural gas (NG) to generate heat, are one of the most popular cooking appliances in Korean households. NG is supplied through gas pipes to individual households, and the burner is lit when a spark ignites the NG. By contrast, an induction cooktop is a cooking appliance that generates heat using electricity. The strong magnetic field generated from the electricity meets the metal and creates resistance, which generates heat. Since no flame is seen and there is no direct heat transfer, the induction cooktop itself stays cold while the pot on the induction cooktop is heated.

Until a few years ago, induction cooktops were only used in Korea in places sensitive to fire, including restaurants and accommodation facilities. However, as the convenience and safety of induction cooktops are becoming more widely known, domestic induction cooktops are expanding their market share. A number of studies have shown that induction cooktops give better performance in terms of thermal efficiency [1], emit fewer air pollutants, and greatly enhance public convenience compared to gas stoves [2-5]. Induction cooktops have therefore been bought for both existing apartments, where they replace gas stoves, and newly built apartments in Korea.

Korean households generally prefer to use an induction cooktops rather than a gas stoves because of the greater convenience and the safety features of an induction cooktop. When cooking with a gas stove, harmful gases such as carbon monoxide and formaldehyde are released because of incomplete combustion. The harmful gases emitted from a gas stove adversely affect the human body, so it is 
necessary to ensure continuous ventilation even during cold winters, and the hood must be cleaned frequently [6-12].

There are several merits of using an induction cooktop for cooking food. First, no harmful gases are emitted in the house, so it is more convenient to cook the food [3]. Second, it is difficult to clean the pot stand of a stove, but an induction cooktop is easy to clean because the food does not burn or stick even if it spills. Third, since the container itself is heated, the room temperature is not raised, so that cooking is more comfortable in hot summers. When a gas stove is used, the cooking time is longer if a strong wind is blowing, so the window has to be closed during cooking even in hot summers. In contrast, an induction cooktop is convenient because, since there is no flame, it is not influenced by the wind $[13,14]$. Fourth, gas stoves can only be used when a gas pipe is installed; an induction cooktop has the advantage that it can be used wherever it is located [4]. Fifth, an induction cooktop prevents the container from overheating, and there is little risk of burns and fires. Gas stoves should always be used with caution because of the danger of gas leaks or of flames being transferred. Between 2012 and 2016, a total of 12 people were killed and 212 people injured in fires caused by gas leaks in the home. Last but not least, it is estimated that such fires caused property damage of 2.9 billion won [15]. For these reasons, despite the price of an induction cooktop being higher than that of a gas stove, sales of induction cooktops in Korea in 2016 were 20 percent higher than in the previous year [16].

In summary, it is expected that the demand for induction cooktops will grow in Korea because of their convenience and safety. This may lead to an increase in the demand for residential electricity in Korea. Therefore, information is needed about the convenience and safety benefits of induction cooktops over gas stoves so that policymakers can more accurately predict the demand for electricity. There are some studies in the literature that evaluate the efficiency and safety features of induction cooktops and gas stoves $[1-5,11,13,14]$. However, to the best of the authors' knowledge, there has been little investigation into the convenience and safety benefits of domestic induction cooktops. This is very much needed in order to provide policymakers with usable and quantitative information.

This study seeks to assess the convenience and safety benefits to residents of Korea of induction cooktops over gas stoves. The research uses a contingent valuation (CV) technique. The rest of the paper comprises four sections. Section 2 explains the methodology employed in the study. Section 3 presents the willingness to pay (WTP) model adopted. Section 4 reports the results and discusses them. The paper concludes with a final section.

\section{Methodology}

\subsection{Method: The CV Approach}

According to microeconomic theory, the additional WTP a premium for using an induction cooktop rather than a gas stove can be used as a basis for valuing the convenience and safety benefits of the induction cooktop $[17,18]$. Because a household induction cooktop is convenient for the consumer and has certain safety features, we consider the convenience and safety benefits of using an induction cooktop rather than a gas stove. It can be measured by employing the CV method, which has been the most frequently applied technique in the literature since Arrow et al.'s [19] recommendation. They strongly supported the use of the CV approach in circumstances requiring administrative and/or jurisdictional decision making. Moreover, the CV method is theoretically based on microeconomics [20-23].

\subsection{Sampling and Survey Instrument}

Random sampling is needed in a CV survey to obtain a sample that represents the population well. Thus, the sampling was commissioned by an expert who was affiliated with a professional survey firm and reflected the population characteristics observed from a census by Statistics Korea, the Korean statistical office. More specifically, stratified random sampling was conducted. That is, we divided our nation into 16 strata and implemented random sampling within each stratum. 
The head or housekeeper of the sampled households was selected as the interviewee to derive responsible opinions from the perspective of a household rather than an individual. In addition, we limited the respondents' age to 20-64, because people who are younger or older have difficulties in responding to the WTP question in the Korean situation. The CV survey was administered in the respondents' homes by trained enumerators in person-to-person interviews during September 2016. In-person interviews enable interviewers to explain effectively the object to be valued to the interviewees, to convey easily visual color cards describing the purpose and background information of the survey to them, and eventually to help them to respond to the WTP question without any difficulty. We obtained 1000 useable observations which we will analyze. The number of observations appears to be adequate in that Arrow et al.'s [19] recommendation to use of a total sample size of 1000 respondents was met.

We tested a preliminary survey questionnaire with a group of 30 persons to ascertain the respondents' understandability and clarity. A total of 30 persons from the focus group made a number of comments that could improve the quality of the survey instrument and provided the preliminary distribution of their WTP for the plan's implementation that can provide a set of bid amounts. Reflecting the results of the focus group interview, we finalized the CV survey instrument as follows: (a) descriptions of the objective and background information of the survey; (b) questions concerning the respondents' perceptions and experiences related to the object to be valued; (c) questions on the additional WTP a premium for the use of an induction cooktop rather than a gas stove; and (d) questions regarding the characteristics of the respondents' household.

\subsection{How to Elicit WTP}

We used a dichotomous choice (DC) question format to obtain the information on the respondents' additional WTP a premium for using an induction cooktop rather than a gas stove. In the DC $\mathrm{CV}$, an interviewee is required to state whether she/he has the willingness to accept the payment of an offered bid to achieve a given improvement or not. Thus, the response is 'yes' or 'no'. The DC method has been applied widely since the theoretical analysis of DC CV data was proposed by Hanemann [24] and its use was recommended by Arrow et al. [19]. Moreover, a number of studies endorsed the application of DC questions instead of open-ended questions (e.g., [25-27]). Open-ended questions usually cause large amounts of protest bid responses and do not coincide with the respondents' incentive. On the other hand, DC questions can mitigate protest bid responses and induce incentive-compatible responses.

The DC question methods are usually divided into two parts. The first is a single-bounded (SB) DC format in which just one question about the respondent's WTP is used. The second question method is a double-bounded (DB) DC format whereby a follow-up question is additionally asked to refine the respondent's WTP. The DB DC format can give us a narrower or more efficient range of WTP than the SB DC format because the second question enables us to narrow the range of the respondent's WTP [28]. However, numerous studies have argued that the second question can cause response bias in eliciting WTP responses. The respondent's compliance or resentment arising from the second question may induce her/him to state a false WTP that is greater or smaller than her/his true WTP (e.g., [29,30]). Therefore, the one-and-one-half-bounded (OOHB) DC question method presented in Cooper et al. [31] is employed in this study (e.g., [32-34]). This is because it can selectively exploit the merits of a single-bounded DC format endorsed by Carson and Groves [30] and a double-bounded DC format suggested by Hanemann et al. [28].

\subsection{Payment Vehicle}

The object to be valued in the CV question has not been achieved at present and is in itself hypothetical. Thus, an instrument to immerse people in the hypothetical situation is needed for the CV question. The instrument is usually called the payment vehicle, which means a medium through which the respondents' WTP is paid. The payment vehicle must be determined to allow the respondents to 
accept it persuasively and understandably. Moreover, it should be familiar to them and unrestricted to conventional expenditure. We employed the residential gas bill, because the residential gas bill is the most common in Korea and is clearly related to their actual expenditure [35-37].

The WTP question asked in our CV survey was "Would your household be willing to pay a specified bid for using an induction cooktop rather than a gas stove from the perspective of convenience and safety through an increase in residential gas bills, supposing that the use of an induction cooktop would certainly be guaranteed?"

\section{WTP Model}

\subsection{OOHB DC Model}

The following model comes from Cooper et al. [31]. Let $T, A_{j}$, and $Y_{j}$ be the number of observations, the bid offered to respondent $j$, and respondent $j$ 's WTP. Before conducting the CV survey, sets of two bids, $A_{j}^{L}$ and $A_{j}^{U}\left(A_{j}^{L}<A_{j}^{U}\right)$, should be determined. In the field survey, of those a set is randomly offered to respondent $j$ in the following manner. About 50 percent of respondents are confronted with $A_{j}^{L}$ and asked to decide whether they accept the payment of $A_{j}^{L}$. If they accept the payment, they are additionally faced with $A_{j}^{U}$ and required to state 'yes' or 'no' to $A_{j}^{U}$. Otherwise, no further question is asked. Similarly, the remaining approximate 50 percent of respondents are provided with $A_{j}^{U}$ and urged to decide whether they accept the payment of it. If the answer is 'no', an additional question concerning $A_{j}^{L}$ is asked. Otherwise, no further question is presented.

The list of possible responses when $A_{j}^{L}$ is offered at first are 'yes-yes' $\left(Y_{j}>A_{j}^{U}\right)$, 'yes-no' $\left(A_{j}^{L}<Y_{j}<A_{j}^{U}\right)$, and 'no' $\left(Y_{j}<A_{j}^{L}\right)$. Likewise, the list of possible responses when $A_{j}^{U}$ is supplied at first are 'yes' $\left(Y_{j}>A_{j}^{U}\right)$, 'no-yes' $\left(A_{j}^{L}<Y_{j}<A_{j}^{U}\right)$, and 'no-no' $\left(Y_{j}<A_{j}^{L}\right)$. Thus, the variables describing the six responses are formulated as $I_{j}^{Y Y}, I_{j}^{Y N}, I_{j}^{N}, I_{j}^{Y}, I_{j}^{N Y}$, and $I_{j}^{N N}$ whose value is one if interviewee $j$ 's answer coincides with the superscript and zero if not.

\subsection{Spike Model}

As explained below, $51.1 \%$ of respondents reported zero WTP. Thus, a spike model given in Kriström [38] and Yoo \& Kwak [39] is utilized in this study to model the WTP observations with a number of zeros. An additional question identifying respondents' WTP as a positive value less than the lower bid $\left(A_{j}^{L}\right)$ or zero was asked of the respondents who stated 'no' to the lower bid. The possible responses are 'yes' and 'no.' The former means $0<Y_{j}<A_{j}^{L}$, and the latter indicates $Y_{j}=0$. Consequently, one more binary variable, $I_{j}^{T Y}$, can be defined. Its value is one if respondent $j$ responded 'yes' to the additional question and zero otherwise.

In the spike model, we formulate the distribution function of the WTP, $H_{Y}($ ), as

$$
H_{Y}\left(A ; \gamma_{0}, \gamma_{1}\right)= \begin{cases}{\left[1+\exp \left(\gamma_{0}-\gamma_{1} A\right)\right]^{-1}} & \text { if } A>0 \\ {\left[1+\exp \left(\gamma_{1}\right)\right]^{-1}} & \text { if } A=0 \\ 0 & \text { if } A<0\end{cases}
$$

where $\gamma_{0}$ and $\gamma_{1}$ are the parameters of the WTP distribution. The log-likelihood function for our spike model is

$$
\begin{aligned}
\ln L= & \sum_{j=1}^{T}\left\{I_{j}^{Y} \ln \left[1-H_{Y}\left(A_{j}^{U} ; \gamma_{0}, \gamma_{1}\right)\right]\right. \\
& +\left(I_{j}^{Y N}+I_{j}^{N Y}\right) \ln \left[H_{Y}\left(A_{j}^{U} ; \gamma_{0}, \gamma_{1}\right)-H_{Y}\left(A_{j}^{L} ; \gamma_{0}, \gamma_{1}\right)\right] \\
& +I_{j}^{T Y}\left(I_{j}^{N}+I_{j}^{N N}\right) \ln \left[H_{Y}\left(A_{j}^{L} ; \gamma_{0}, \gamma_{1}\right)-H_{Y}\left(0 ; \gamma_{0}, \gamma_{1}\right)\right] \\
& \left.+\left(1-I_{j}^{T Y}\right)\left(I_{j}^{N}+I_{j}^{N N}\right) \ln H_{Y}\left(0 ; \gamma_{0}, \gamma_{1}\right)\right\}
\end{aligned}
$$


The values for $\gamma_{0}$ and $\gamma_{1}$ maximizing Equation (2) are the maximum likelihood estimator, which is known to be consistent and asymptotically efficient. It is necessary to compute the mean WTP, a location value for the respondent's WTP. We use the usual formula for calculating the average and compute the mean WTP as

$$
E(Y)=\int_{0}^{\infty}\left[1-H_{Y}\left(A ; \gamma_{0}, \gamma_{1}\right)\right] d A-\int_{-\infty}^{0} H_{Y}\left(A ; \gamma_{0}, \gamma_{1}\right) d A=\left(1 / \gamma_{1}\right) \ln \left[1+\exp \left(\gamma_{0}\right)\right]
$$

\section{Estimation Result}

\subsection{Data}

From the results from a focus group interview, the list of bids was determined as KRW 20/100, 50/150, 100/200, 150/300, 200/400, 300/500, and 400/700. When the survey was conducted, the exchange rate was USD $1.0=$ KRW 1107. Results reflect data from 1000 usable observations. The final data were judged to be of good quality by both enumerators and supervisors. The number of the responses to each bid is reported in Table 1. A total of 511 respondents stated zero WTP a premium for using an induction cooktop rather than a gas stove. This portrays our strategy of using the spike model as appropriate.

Table 1. Distribution of responses by bid amount.

\begin{tabular}{|c|c|c|c|c|c|c|c|c|c|c|}
\hline \multirow{2}{*}{\multicolumn{2}{|c|}{$\begin{array}{c}\text { Bid } \\
\text { Amount }^{a}\end{array}$}} & \multicolumn{4}{|c|}{ Lower Bid Is Presented as the First Bid (\%) ${ }^{b}$} & \multicolumn{5}{|c|}{ Upper Bid Is Presented as the First Bid (\%) ${ }^{b}$} \\
\hline & & \multirow{2}{*}{$\begin{array}{c}\text { 'Yes-Yes' } \\
23(16.1)\end{array}$} & \multirow{2}{*}{$\begin{array}{c}\text { 'Yes-No' } \\
26(18.2)\end{array}$} & \multirow{2}{*}{$\begin{array}{c}\text { 'No-Yes' } \\
1(0.7)\end{array}$} & \multirow{2}{*}{$\begin{array}{l}\text { No-No' } \\
22(15.4)\end{array}$} & \multirow{2}{*}{$\begin{array}{c}\text { 'Yes' } \\
30(21.0)\end{array}$} & \multirow{2}{*}{$\begin{array}{c}\text { 'No-Yes' } \\
15(10.5)\end{array}$} & \multirow{2}{*}{$\begin{array}{c}\text { 'No-No-Yes' } \\
0(0.0)\end{array}$} & \multirow{2}{*}{$\begin{array}{c}\text { 'No-No-No' } \\
26(18.2)\end{array}$} & \multirow{2}{*}{$\begin{array}{c}\text { Sample Size } \\
143(100.0)\end{array}$} \\
\hline 20 & 100 & & & & & & & & & \\
\hline 50 & 150 & $19(13.3)$ & $15(10.5)$ & $1(0.7)$ & $36(25.2)$ & $21(14.7)$ & $10(7.0)$ & $4(2.8)$ & $37(25.9)$ & $143(100.0)$ \\
\hline 100 & 200 & $16(11.2)$ & $12(8.4)$ & $3(2.1)$ & $40(28.0)$ & $22(15.4)$ & $8(5.6)$ & $6(4.2)$ & $36(25.2)$ & $143(100.0)$ \\
\hline 150 & 300 & $11(7.7)$ & $14(9.8)$ & $6(4.2)$ & $40(28.0)$ & $25(17.5)$ & $7(4.9)$ & $4(2.8)$ & $36(25.2)$ & $143(100.0)$ \\
\hline 200 & 400 & $12(8.5)$ & $15(10.6)$ & $5(3.5)$ & $39(27.5)$ & $20(14.1)$ & $10(7.0)$ & $8(5.6)$ & $33(23.2)$ & $142(100.0)$ \\
\hline 300 & 500 & $10(7.0)$ & $10(7.0)$ & $8(5.6)$ & $44(30.8)$ & 15 (10.5) & $7(4.9)$ & $8(5.6)$ & $41(28.7)$ & $143(100.0)$ \\
\hline 400 & 700 & $10(7.0)$ & $10(7.0)$ & $7(4.9)$ & $45(31.5)$ & $10(7.0)$ & $15(10.5)$ & $10(7.0)$ & $36(25.2)$ & $143(100.0)$ \\
\hline \multicolumn{2}{|c|}{ Sample size } & $101(20.2)$ & $102(10.2)$ & $31(3.1)$ & $266(26.6)$ & $143(14.3)$ & $72(7.2)$ & $40(4.0)$ & $245(24.5)$ & $1000(100.0)$ \\
\hline
\end{tabular}

Note: ${ }^{a}$ The unit is Korean won and USD 1 was approximately equal to KRW 1107 at the time of the survey;

$\mathrm{b}$ The numbers in parentheses beside the number of responses are the percentage of sample size.

\subsection{Results from Estimating the OOHB DC Spike Model}

Table 2 presents the outcomes of estimating the OOHB DC spike model. The coefficient for the bid is statistically meaningful at the $1 \%$ level and has a negative sign. This implies that a lower bid amount makes it more likely that the respondent will answer 'yes' to the bid. The spike is estimated to be 0.5134 . This value is quite close to the sample proportion (51.1\%). Judging from the Wald statistic, the estimated equation has a statistical significance. Thus, we can proceed to any interpretation of the estimated coefficients with statistical meaningfulness. The mean household WTP a premium for using an induction cooktop rather than a gas stove is computed to be KRW 207 (USD 0.19) per cubic meter of residential gas, which possesses statistical meaningfulness. The confidence intervals calculated adopting Krinsky and Robb's [40] method are also presented in Table 2. 
Table 2. Estimation results of the spike model.

\begin{tabular}{|c|c|}
\hline Variables & Coefficient Estimates ${ }^{d}$ \\
\hline Constant & $-0.0535(-0.85)$ \\
\hline $\mathrm{Bid}^{\mathrm{a}}$ & $-0.0322(-17.67) \#$ \\
\hline Spike & $0.5134(32.53)^{\#}$ \\
\hline Mean WTP per cubic meter of residential gas & KRW 207 (USD 0.19) \\
\hline$t$-value & $16.49^{\#}$ \\
\hline $95 \%$ confidence intervals $b$ & KRW 184-234 (USD 0.17-2.11) \\
\hline $99 \%$ confidence intervals $b$ & KRW 178-244 (USD 0.16-0.22) \\
\hline Number of observations & 1000 \\
\hline Log-likelihoods & -1216.98 \\
\hline Wald statistics ${ }^{c}$ ( $p$-values) & $271.95(0.000)$ \\
\hline
\end{tabular}

Notes: ${ }^{a}$ The unit is 1000 Korean won and 1.0 USD was approximately equal to KRW 1107 at the time of the survey; $\mathrm{b}$ The confidence intervals are calculated using the Monte Carlo simulation technique of Krinsky \& Robb [40], with 5000 replications; ${ }^{\mathrm{C}}$ The null hypothesis is that all the parameters are jointly zero, and the corresponding $p$-value is reported in parentheses beside the statistic; ${ }^{\mathrm{d}}$ The numbers in parentheses beside the coefficient estimates are the $t$-values, computed from the analytic second derivatives of the log-likelihood; \# indicates statistical significance at the $1 \%$ level.

\subsection{Estimation Results of the Model with Covariates}

Let $z_{j}$ and $\delta$, respectively, be the covariate vector for respondent $j$ and the corresponding parameter vector to be estimated. To investigate how covariates influence the probability of stating 'yes' to an offered bid, we estimate the model with covariates, where $\gamma_{0}$ in Equation (1) is simply replaced with $\gamma_{0}+z_{j}^{\prime} \delta$. The socio-economic variables used for the covariates and their sample statistics are described in Table 3. For example, $50 \%$ of the participants were male, and the average household income was KRW 4.33 million (USD 3910) per household per month.

Table 3. Definitions and sample statistics of the variables.

\begin{tabular}{cccc}
\hline Variables & Definitions & Mean & Standard Deviation \\
\hline Gender & The respondent's gender $(1=$ male; $0=$ female) & 0.50 & 0.50 \\
Family & The size of the respondent's household (unit: persons) & 3.31 & 1.07 \\
Education & The respondent's education level in years & 14.01 & 2.42 \\
Income & The household's monthly income before tax deduction & 4.33 & 1.82 \\
\hline
\end{tabular}

Table 4 contains the results from estimating the OOHB DC spike model including some socio-economic variables. In this model, we can compute the spike as $\left[1+\exp \left(\gamma_{0}+\bar{z}^{\prime} \hat{\delta}\right)\right]^{-1}$, where $\bar{z}$ is the vector of the mean values given in Table 3 and $\hat{\delta}$ is the vector of the coefficient estimates presented in Table 4. The spike is calculated as 0.5143 , which is same to the value in Table $2(0.5134)$. The mean WTP as a premium for using an induction cooktop rather than a gas stove is calculated to be KRW 203 (USD 0.18) per cubic meter of residential gas. This value is also close to that in Table 2 (KRW 207). Adding covariates to the model does not significantly change the estimates for the spike and mean WTP.

The estimates of the coefficients for gender, family, education, and income variables all have statistical meaningfulness at the $5 \%$ level and are negative, negative, positive, and positive. Female respondents have a higher probability of answering 'yes' to a bid than male respondents. Respondents whose household size is smaller have a higher tendency to report 'yes' to an offered bid than others. More educated respondents are more likely to say 'yes' to a given bid than others. Household income has a positive relation to the probability of stating 'yes' to a presented bid. 
Table 4. Estimation results of the spike model with covariates.

\begin{tabular}{|c|c|c|}
\hline Variables $^{a}$ & Estimates & $t$-Values \\
\hline Constant & -0.7063 & $-1.84 *$ \\
\hline Bid $^{b}$ & -0.0328 & $-16.89^{\#}$ \\
\hline Gender & -0.2978 & $-2.45^{* *}$ \\
\hline Family & -0.1654 & $-2.72 \#$ \\
\hline Education & 0.0685 & $2.64^{\#}$ \\
\hline Income & 0.8924 & $2.56^{\#}$ \\
\hline Spike & 0.5143 & $32.55^{\#}$ \\
\hline Mean WTP per cubic meter of residential gas & \multicolumn{2}{|c|}{ KRW 203 (USD 0.18) } \\
\hline$t$-value & \multicolumn{2}{|c|}{$16.15^{\#}$} \\
\hline $95 \%$ confidence interval ${ }^{b}$ & \multicolumn{2}{|c|}{ KRW 180-230 (USD 0.16-0.21) } \\
\hline $99 \%$ confidence interval $^{b}$ & \multicolumn{2}{|c|}{ KRW $173-240$ (USD $0.16-0.22$ ) } \\
\hline Number of observations & \multicolumn{2}{|c|}{1000} \\
\hline Log-likelihood & \multicolumn{2}{|c|}{-1205.172} \\
\hline Wald statistic ${ }^{\mathrm{c}}$ ( $p$-value) & \multicolumn{2}{|c|}{$260.87(0.000)$} \\
\hline
\end{tabular}

Notes: The variables are defined in Table $1 .{ }^{\text {a }}$ The unit is KRW 1000 and USD 1.0 was approximately equal to KRW 1107 at the time of the survey; ${ }^{b}$ The confidence intervals are calculated by the use of the Monte Carlo simulation technique suggested by Krinsky and Robb [40] with 5000 replications; ${ }^{\mathrm{C}}$ The null hypothesis is that all the parameters are jointly zero, and the corresponding $p$-value is reported in the parentheses next to the statistic; ${ }^{*}{ }^{* *}$, and * indicate statistical significance at the $1 \%, 5 \%$, and $10 \%$ levels, respectively.

\subsection{Discussion of the Results}

No assessment of the convenience and safety benefits of using an induction cooktop rather than a gas stove has been reported in the literature. Thus, it seems that the issue is not an important research topic in most countries. In Korea, however, information about the convenience and safety benefits of using an induction cooktop rather than a gas stove is needed. As explained above, the use of induction cooktops is expanding quickly in Korea since many people have become interested in their convenience and safety features. Consequently, uncovering the convenience and safety benefits to consumers of using an induction cooktop instead of a gas stove is meaningful for Korea.

Before we expand the sample results to the whole population, it is necessary to examine whether the sample represents the national population well. In this regard, from Statistics Korea we founded three socio-economic variables through which we can compare the characteristics for the sample with those for the population. They are the household's monthly income, the size of the household, and the ratio of female respondents. At the time of survey, the values were KRW 4.37 million, 3.17 persons, and $49.9 \%$, respectively. Our sample averages are KRW 4.33 million, 3.31 persons, and $50.0 \%$. The former values are not significantly different from the latter values. In addition, with the help of the trained interviewers who were affiliated with a professional survey firm, almost 100 percent of the interviewed households answered to all questions in the CV survey.

From our results we estimate that the mean additional WTP a premium for using an induction cooktop rather than a gas stove is KRW 207 (USD 0.19) per cubic meter of residential gas. Given that in 2015 the average price of residential gas for cooking was KRW 775.13 (USD 0.70) per cubic meter, the convenience and safety benefits that ensue from using an induction cooktop instead of a gas stove amount to $26.7 \%$ of the average price of residential gas for cooking. This suggests that Korean residents would be willing to pay a significant premium to use an induction cooktop instead of a gas stove. Changing from gas stoves to induction cooktops would thus be preferred for Korean households.

The average prices of residential gas and residential electricity in 2015 were KRW 73.12 and 143.83 per calorie, respectively. The gap was KRW $70.70 \mathrm{KRW}$ per calorie. The estimated mean premium for induction cooktops over gas stoves can be converted to KRW 19.53 per calorie. Therefore, the households with lower WTP for using an induction cooktop instead of a gas stove than the gap are not likely to use the induction cooktops. On the other hand, the households with higher WTP for using an induction cooktop instead of a gas stove than the gap tend to use the induction cooktops. These results can be utilized in predicting the 
residential electricity demand for the induction cooktops with respect to the price of residential electricity relative to that of residential gas price, since an induction cooktop is a substitute for a gas stove.

The Korean government is preparing a long-term national plan for electricity, the 8th Basic Plan for Long-term Electricity Supply and Demand (2017-2031). The plan includes the long-term outlook for electricity supply and demand, plans for generation facilities, transmission facilities, and transformation facilities, and plans for electricity demand management. The initial task when drawing up the plan is to forecast the electricity demand. In doing this, a number of issues, such as predictions of the gross domestic product, the price of electricity, temperature, and how many electric vehicles will be on the roads, are considered. An important issue to be considered when forecasting the electricity demand is how the supply of induction cooktops will be expanded and how far the expansion will affect residential electricity use. The results from our study can be used in looking into this issue. If the gap between the price for residential electricity and the price for residential gas is less than the WTP value, households will increase their demand for residential electricity because they will replace their gas stoves with induction cooktops. These points should be reflected in forecasting the demand for residential electricity.

\section{Conclusions and Policy Implications}

The induction cooktop has emerged as a substitute for the gas stove because of the greater convenience and the safety features of an induction cooktop. An induction cooktop does not emit air pollutants indoors and thus has an enhanced public convenience and safety compared to a gas stove. The preference of Korean households for induction cooktops has increased, and this will cause a rapid increase in the supply of induction cooktops. Sales of induction cooktops increased from 456,300 units in 2015 to 555,900 units in 2016, a rise of 20\%. Sales of gas stoves fell by $2.0 \%$ in 2016 compared to 2015 . This can affect the use of residential electricity. Thus, information about the convenience and safety benefits of using an induction cooktop rather than a gas stove is needed for policymakers.

The average electricity consumption of the Korean households was $385 \mathrm{kWh}$ per month during 2016. The conversion from a gas stove to an induction cooktop is expected to increase a household's electricity consumption by $45 \mathrm{kWh}$ when a household uses an induction cooktop consuming $1500 \mathrm{~W}$ of electricity one hour per a day. Thus, the conversion implies an increase of $11.7 \%$ in household electricity consumption about. If a $20 \%$ increase in the conversion arises, total consumption of residential electricity by households will be increased by about $2.3 \%$.

The information helps policymakers to make accurate predictions of the demand for residential electricity. However, to the best of the authors' knowledge, the convenience and safety benefits of using an induction cooktop have rarely been investigated in the literature. Economic theory indicates that the convenience and safety benefits of using an induction cooktop rather than a gas stove can be measured by finding the consumer's additional WTP for such use. To this end, the article applied the CV approach in a national survey of 1000 randomly chosen households. Moreover, the OOHB DC spike model is adopted to model the WTP observations with zero responses.

The Korean government is scheduled to establish the 8th Basic Plan for Long-term Electricity Supply and Demand (2017-2031). The forecasting of electricity demand is critical for establishing the long-term national plan for electricity. Thus, the expansion in the supply of induction cooktops and how this expansion will affect residential electricity use is an important issue in forecasting electricity demand. This study has attempted to investigate this issue. The convenience and safety benefits of the induction cooktop over the gas stove were estimated to be KRW 207 (USD 0.19) per cubic meter of residential gas. This value amounts to approximately $26.7 \%$ of the average 2015 price for residential gas, KRW 775 (USD 0.70) per cubic meter.

Given the constraints on power generation, correct and valid estimates to forecast electricity demand are required to establish an economically feasible plan. If the gap between the price for residential electricity and the price for residential gas is less than the additional WTP a premium for using an induction cooktop rather than a gas stove (KRW 207 or USD 0.19), the demand for residential electricity because of 
the use of induction cooktops would be expected to increase. Therefore, it is necessary to understand the planned expansion and to use this information to establish policies for the electricity supply in accordance with the increased demand for residential electricity. It should be noted that the research findings may be unique to Korea. In order to obtain more generalized insights about a premium for induction cooktops over gas stoves, future studies should apply the framework adopted in this study to other countries and compare the findings from Korea with those from other countries. The message of the task will be all the more useful as there is little evidence concerning this issue.

Acknowledgments: This work was supported by the Korea Institute of Energy Technology Evaluation and Planning (KETEP) and the Ministry of Trade, Industry \& Energy (MOTIE) of the Republic of Korea (No. 20164030201060).

Author Contributions: All the authors contributed immensely. Hyo-Jin Kim designed the ideas and analyzed the data; Seul-Ye Lim wrote the majority of the manuscript; and Seung-Hoon Yoo contributed the main idea and various scientific insights and helped to edit the manuscript.

Conflicts of Interest: The authors declare no conflict of interest.

\section{References}

1. United States Department of Energy. Volume 2: Potential Impact of Alternative Efficiency Levels for Residential Cooking Products. In Technical Support Document for Residential Cooking Products; United States Department of Energy: Washington, DC, USA, 2011.

2. Moreland, W.C. The induction range: Its performance and its development problems. IEEE Trans. Ind. Appl. 1973, 1, 81-85. [CrossRef]

3. Palmes, E.D.; Tomczyk, C.; DiMattio, J. Average $\mathrm{NO}_{2}$ concentrations in dwellings with gas or electric stoves. Atmos. Environ. 1977, 11, 869-872.

4. Fields, R. Restaurant Success by the Numbers: A Money-Guy's Guide to Opening the Next Hot Spot; Ten Speed Press: Berkeley, CA, USA, 2011.

5. Acero, J.; Carretero, C.; Alonso, R.; Burdio, J.M. Quantitative evaluation of induction efficiency in domestic induction heating applications. IEEE Trans. Magn. 2013, 49, 1382-1389. [CrossRef]

6. Bromly, J.H.; Johnston, R.C.R.; Barnes, F.J.; Little, L.H. Effect of vitiation on trace pollutants from domestic gas appliances. J. Inst. Energy 1985, 58, 188-196.

7. Traynor, G.W.; Girman, J.R.; Apte, M.G.; Dillworth, J.F.; White, P.D. Indoor air pollution due to emissions from unvented gas-fired space heaters. J. Air Pollut. Control Assoc. 1985, 35, 231-237. [CrossRef] [PubMed]

8. Moschandreas, D.J.; Relwani, S.M.; Billick, I.H.; Macriss, R.A. Emission rates from range-top burners-Assessment of measurement methods. Atmos. Environ. 1987, 21, 285-289. [CrossRef]

9. Barnes, F.J.; Bromly, J.H.; Edwards, T.J.; Mandyczewsky, R. $\mathrm{NO}_{(\mathrm{x})}$ emissions from radiant gas burners. J. Inst. Energy 1988, 61, 184-188.

10. Raiyani, C.V.; Shah, S.H.; Desai, N.M.; Venkaiah, K.; Patel, J.S.; Parikh, D.J.; Kashyap, S.K. Characterization and problems of indoor pollution due to cooking stove smoke. Atmos. Environ. Part A Gen. Top. 1993, 27, 1643-1655. [CrossRef]

11. Ko, Y.C.; Lin, T.H. Emissions and efficiency of a domestic gas stove burning natural gases with various compositions. Energy Convers. Manag. 2003, 44, 3001-3014. [CrossRef]

12. Xing, R.; Hanaoka, T.; Kanamori, Y.; Masui, T. Greenhouse gas and air pollutant emissions of China's residential sector: The importance of considering energy transition. Sustainability 2017, 9, 614. [CrossRef]

13. Acero, J.; Burdio, J.M.; Barragan, L.A.; Navarro, D.; Alonso, R.; Ramon, J.; Garde, I. Domestic induction appliances. IEEE Ind. Appl. Mag. 2010, 16, 39-47. [CrossRef]

14. Egalon, J.; Caux, S.; Maussion, P.; Souley, M.; Pateau, O. Multiphase system for metal disc induction heating: Modeling and RMS current control. IEEE Trans. Ind. Appl. 2012, 48, 1692-1699. [CrossRef]

15. Ministry of Public Safety and Security. National Fire Data System. Available online: http://www.nfds.go. $\mathrm{kr}$ /fr_base_0001.jsf (accessed on 8 May 2017).

16. Gas News. Available online: http://www.gasnews.com/news/articleView.html?idxno=77091 (accessed on 8 May 2017).

17. Kim, Y.; Park, Y.; Lee, J.D.; Lee, J. Using stated-preference data to measure the inconvenience cost of spam among Korean e-mail users. Appl. Econ. Lett. 2006, 13, 795-800. [CrossRef] 
18. Yoo, S.H.; Shin, C.O.; Kwak, S.J. Inconvenience cost of spam mail: A contingent valuation study. Appl. Econ. Lett. 2006, 13, 933-936. [CrossRef]

19. Arrow, K.; Solow, R.; Portney, P.R.; Leamer, E.E.; Radner, R.; Schuman, H. Report of the NOAA panel on contingent valuation. Fed. Regist. 1993, 58, 4601-4614.

20. Yoo, S.-H.; Kwak, S.-Y. Willingness to pay for green electricity in Korea. Energy Policy 2009, 37, 5408-5416. [CrossRef]

21. Adaman, F.; Karalı, N.; Kumbaroğlu, G.; Or, İ.; Özkaynak, B.; Zenginobuz, Ü. What determines urban households' willingness to pay for $\mathrm{CO}_{2}$ emission reductions in Turkey: A contingent valuation survey. Energy Policy 2011, 39, 689-698. [CrossRef]

22. Guo, X.; Liu, H.; Mao, X.; Jin, J.; Chen, D.; Cheng, S. Willingness to pay for renewable electricity: A contingent valuation study in Beijing, China. Energy Policy 2014, 68, 340-347. [CrossRef]

23. Lim, S.Y.; Kim, H.J.; Yoo, S.H. Public's willingness to pay a premium for bioethanol in Korea: A contingent valuation study. Energy Policy 2017, 101, 20-27. [CrossRef]

24. Hanemann, W.M. Welfare evaluations in contingent valuation experiments with discrete responses. Am. J. Agric. Econ. 1984, 66, 332-341. [CrossRef]

25. Bateman, I.J.; Carson, R.T.; Day, B.; Haneman, M.; Hanley, N.; Hett, T.; Jones-Lee, M.; Loomes, G.; Mourato, S.; Ozdemiroglu, E.; et al. Economic Valuation with Stated Preference Techniques: A Manual; Edward Elgar: Cheltenham, UK, 2002.

26. Champ, P.A.; Boyle, K.J.; Brown, T.C. A Primer on Nonmarket Valuation; Kluwer Academic Publishers: Dordrecht, The Netherlands, 2004.

27. Johnston, R.J.; Boyle, K.J.; Adamowicz, W.; Bennett, J.; Brouwer, R.; Cameron, T.A.; Hanemann, W.M.; Hanley, N.; Ryan, M.; Scarpa, R.; et al. Contemporary Guidance for Stated Preference Studies. J. Assoc. Environ. Resour. Econ. 2017, 4, 319-405. [CrossRef]

28. Hanemann, W.M.; Loomis, J.; Kanninen, B.J. Statistical efficiency of double-bounded dichotomous choice contingent valuation. Am. J. Agric. Econ. 1991, 73, 1255-1263. [CrossRef]

29. Bateman, I.J.; Langford, I.H.; Jones, A.P.; Kerr, G.N. Bound and path effects in double and triple bounded dichotomous choice contingent valuation. Resour. Energy Econ. 2001, 23, 191-213. [CrossRef]

30. Carson, R.T.; Groves, T. Incentive and informational properties of preference questions. Environ. Resour. Econ. 2007, 37, 181-210. [CrossRef]

31. Cooper, J.C.; Hanemann, M.; Signorello, G. One and one-half bound dichotomous choice contingent valuation. Rev Econ. Stat. 2002, 84, 742-750. [CrossRef]

32. Kim, H.-Y.; Park, S.-Y.; Yoo, S.-H. Public acceptability of introducing a biogas mandate in Korea: A contingent valuation study. Sustainability 2016, 8, 1087. [CrossRef]

33. Park, S.-Y.; Lim, S.-Y.; Yoo, S.-H. The economic value of the national meteorological service in the Korean household sector: A contingent valuation study. Sustainability 2016, 8, 834. [CrossRef]

34. Lim, S.Y.; Jin, S.J.; Yoo, S.H. The economic benefits of the Dokdo seals restoration project in Korea: A contingent valuation study. Sustainability 2017, 9, 968. [CrossRef]

35. Lim, K.M.; Lim, S.Y.; Yoo, S.H. Estimating the economic value of residential electricity use in the Republic of Korea using contingent valuation. Energy 2014, 64, 601-606. [CrossRef]

36. Egan, K.J.; Corrigan, J.R.; Dwyer, D.F. Three reasons to use annual payments in contingent valuation surveys: Convergent validity, discount rates, and mental accounting. J. Environ. Econ. Manag. 2015, 72, 123-136. [CrossRef]

37. Kim, H.J.; Lim, S.Y.; Yoo, S.H. Is the Korean public willing to pay for a decentralized generation source? The case of natural gas-based combined heat and power. Energy Policy 2017, 102, 125-131. [CrossRef]

38. Kriström, B. Spike models in contingent valuation. Am. J. Agric. Econ. 1997, 79, 1013-1023. [CrossRef]

39. Yoo, S.H.; Kwak, S.J. Using a spike model to deal with zero response data from double bounded dichotomous choice contingent valuation surveys. Appl. Econ. Lett. 2002, 9, 929-932. [CrossRef]

40. Krinsky, I.; Robb, A.L. On approximating the statistical properties of elasticities. Rev. Econ. Stat. 1986, 68, 715-719. [CrossRef]

(C) 2017 by the authors. Licensee MDPI, Basel, Switzerland. This article is an open access article distributed under the terms and conditions of the Creative Commons Attribution (CC BY) license (http://creativecommons.org/licenses/by/4.0/). 